\section{Charcot in Morocco}

Toby Gelfand (University of Ottawa Press). I am suspicious of people with neat handwriting. If one has the time to legibly record one's ideas then perhaps one doesn't have enough of them, is my thinking. By this standard, Jean-Martin Charcot, the father of neurology, would be above any reproach. During his career, Charot's clinical acumen generated no fewer than twelve partly or wholly owned eponyms now listed on Wikipedia, while Charcot in Morocco displays samples of a largely unreadable calligraphy suggestive of a busy brain.

Charcot in Morocco, by University of Ottawa historian Toby Gelfand, is based on a travel diary Charcot wrote in 1887 . The book is slight, but heavy with ideas of language, history and culture.

Gelfand gamely provides his English translation of Charcot's diary and the presumably painstaking transcription of the scarcely decipherable French original, letting the reader examine his choices as a translator. For example, a group of "scelerats" at a penal colony "auxquels on donnerait le bon Dieu sans confession" become "rascals ... who looked like butter wouldn't melt in their mouths." Is the true grain of Charcot obscured by the brush of translation? Surely yes: the translator must contribute something. But it starts one to thinking about clarity.

And there are some provocative obscurities. Why did Charcot record this specific trip? What was Gelfand's reason for sharing this record?

The answer to the latter question might be revealed in the introduction: Gelfand seems preoccupied with Charcot's own apparent fascination with Moroccan Jews. Careful to avoid excessive postcolonial hand-wringing, Gelfand even prefers not to use the term "anti-Semite" at all. But in calling Charcot a "Semitist," referring to a condescending and Eurocentric interest, there is an approbation of which Edward Said would have approved.

Charcot never misses a chance to describe someone as "un juif" (and is equally thorough in his use of "maure" and "arabe"). His most involved pas- sage, a stunningly detailed description of a Jewish wedding, seems at least faintly supercilious. Or am I simply sensitive to the issue - is my reading obscured because Gelfand brought it up first?

The trouble may be that, as is customary, I started with the introduction. Perhaps Charcot in Morocco is most legibly enjoyed as I have described it here: have a look at both the French and English texts, and save the introduction for last. — Paul Moorehead, Janeway Child Health and Rehabilitation Centre, St. John's, NL

\section{CMAJ 2014. DOI:10.1503/cmaj.130783}

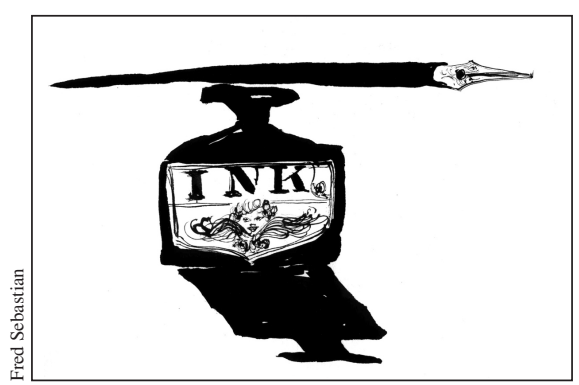

Shakespeare's Tremor and Orwell's Cough: The Medical Lives of Famous Writers

John J. Ross (St. Martin's Press). For would-be writers, the provenance of Shakespeare's Tremor and Orwell's Cough: The Medical Lives of Famous Writers is noteworthy. It began as a PowerPoint talk about syphilis for medical grand rounds. Infectious disease specialist John J. Ross wanted to enliven his presentation on genital infections with a few lines from Shakespeare. He noted, "I had a recollection from my undergraduate days that the Bard was fond of joking about the great pox. I dusted off my battered copy of the Riverside Shakespeare and started leafing through it. Holy crap, I thought, there is a lot of stuff here on syphilis."

The book is medical literature — but a mixed genre. There's definitely evidence cited, more than a few facts and some historical fiction. Ross serves up much delicious speculation, diagnostic puzzles, and a plethora of grotesque details about assorted physical and mental ailments that afflicted ten literary giants.
He begins with Shakespeare's tremor and ends with Orwell's bronchiectasis, and along the way, makes a case for Jonathan Swift's dementia and describes "the many maladies of Herman Melville." All the writers lived and died before the mid-twentieth century effectively the beginning of the modern medical era. The chapters about Shakespeare and Orwell were first published in Clinical Infectious Diseases.

Ross's energetic style and narrative structure are reminiscent of Max Haines, the syndicated newspaper columnist of "Crime Flashback." Occasionally he drops into a plain English, doctor-teacher mode for the benefit of nonphysician readers. To be fair, Ross is more measured and less sensational in his storytelling than Haines; still, he's fond of a hyperbolic turn of phrase, a scatological flourish or a juicy tidbit of sexual history.

In one paragraph he describes how Jonathan Swift's father may have been infected by scabies: "a mite that chomps its way through the superficial layers of the skin, trailing eggs and feces as it goes." In Ross's view it may have been terminal scabies, as contemporary treatments for undifferentiated itching diseases often involved the application of mercury ointment. Mercury poisoning, we learn, can lead to "bad breath, rotten gums and uncontrolled drooling" - seldom fatal, but a nasty trio nevertheless, and perhaps a prelude to papa Swift's mercury-induced renal failure.

Be prepared to have your eyes opened about "amateur M.D." Jack London's demise, and your biographical assumptions about the Brontë sisters questioned. "More claptrap has been written about the Brontës than any other group of English writers." Thanks to tons of research and a lively prose style, Ross brings to life the persons wielding the pen. If you have your favourites among masterpieces like The Call of the Wild or Wuthering Heights, you likely will not read them in the same way again. - Vincent Hanlon, Physician and Family Support Program, Alberta Medical Association, Calgary, Alta. 